\title{
Effect of Bite Opening on the Correction of Dental Anterior Cross Bite - A Novel Approach
}

$\begin{array}{ll}\text { Abul Khair Zalan } & \text { BDS } \\ \text { Anser Maxood }^{2} & \text { BDS, MSc, FRACDS, FICD, MAAPD } \\ \text { Mohammad Haroon Dalili }^{3} & \text { BDS, MSc } \\ \text { Hira Zaman }^{4} & \text { BDS, MDS } \\ \text { Khadeejah Khalil Zubairy }^{5} & \text { BDS } \\ \text { Palwasha Babar }^{6} & \text { BDS, MDS } \\ \text { Miraat Anser }^{7} & \text { BDS }\end{array}$

OBJECTIVES: To correct dental origin anterior crossbite by placement of Glass Ionomer cement occlusal stops on mandibular first permanent molars for maximum of two weeks.

METHODOLOGY: 16 patients (age: 7-11 years) with dental anterior crossbite were treated by placement of Glass Ionomer cement occlusal stops on mandibular first permanent molars for maximum of 2 weeks to create $1 \mathrm{~mm}$ anterior open bite. The patients were then recalled after 1 month, 3 months and 6 months for follow up visits. Fisher's exact test applied using SPSS version \# 25.

DISCUSSION: Pediatric dentists frequently encounter patients with anterior crossbite in mixed dentition stage. This usually requires an appliance therapy for correction. However, unlike previous modalities, this novel approach of correcting crossbite by opening the bite is simple, economical and does not depend on patient compliance.

RESULTS: 13 out of 16 patients were treated successfully within two weeks of placement of occlusal stops. Follow-up at six months showed no relapse in any of the corrected cases.

CONCLUSION: Placement of glass ionomer cement occlusal stops for two weeks on mandibular first permanent molars is an easy approach to correct dental anterior crossbite.

KEYWORDS: Crossbite, Malocclusion, Glass ionomer cement, Corrective orthodontics

HOW TO CITE: Zalan AK, Maxood A, Dalili MH, Zaman H, Zubairy KK, Babar P, Anser M. Effect of bite opening on the correction of dental anterior cross bite - A novel approach. J Pak Dent Assoc 2021;30(2):107-112.

DOI: https://doi.org/10.25301/JPDA.302.107

Received: 18 August 2020, Accepted: 02 January 2021

\section{INTRODUCTION}

$\mathrm{A}$ nterior cross bite is a type of malocclusion in which maxillary anterior teeth are placed lingual to the mandibular anterior teeth. ${ }^{1,2}$ It can be a major

1. Post Graduate MDS Resident, Department of Pediatric Dentistry, Children Hospital, Pakistan Institute Medical Sciences, Islamabad.

2. Professor, Head Of Department, Department of Operative and Pediatric Dentistry, Pakistan Institute Medical Sciences, Islamabad.

3. Post Graduate Resident MSc, Dental Sciences for Clinical Pratice, Barts and the London School of Medicine and Dentistry.

4. Senior Registrar, Department of Operative Dentistry, University College of Medicine and Dentistry Lahore.

5. House Officer, Department of Pediatric Dentistry, Pakistan Institute Medical Sciences, Islamabad.

6. Assistant Professor, Department of Pediatric Dentistry, University College of Medicine and Dentistry Lahore.

7. Post Graduate MDS Resident, Department of Pediatric Dentistry, Pakistan Institute Medical Sciences, Islamabad.

Corresponding author: “Abul Khair Zalan” < zalanjan@yahoo.com > esthetic and functional concern for the parents of a growing child. Crossbite can involve a single tooth or multiple teeth. ${ }^{3}$ Its prevalence is reported to be between 1.6 and $7.9 \%{ }^{1,4} \mathrm{In}$ some studies its prevalence in children is reported to be as high as $27 \% .3,5$

Anterior crossbite may be dental, skeletal or functional in origin. ${ }^{2}$ In dental crossbite, only tipping /lingual inclination of maxillary incisors are present with no dental compensation and basal bone abnormality. ${ }^{6}$ It is usually present in early mixed dentition phase. On the other hand, skeletal type of anterior crossbite is either because of an excessive mandibular growth or a deficient maxilla. Functional crossbite, which is also called pseudo-class III malocclusion, is because of the forward posture of mandible from its centric position. ${ }^{7}$ It might be present because of occlusal premature contacts. Dental anterior crossbite has multiple etiological factors, 
which include lingual path of eruption of maxillary incisors, retained deciduous incisors, deficiency of space, supernumerary teeth, odontomas, repaired cleft lip, inadequate arch length, delayed exfoliation of deciduous teeth and trauma to the primary teeth which results in lingual displacement of developing permanent incisors. ${ }^{8,9}$

Treatment of anterior crossbite should be instigated immediately after the diagnosis whether the patient is in primary or mixed dentition stage. ${ }^{5}$ Early treatment allows harmonious growth and development of bones and prevents permanent changes in the occlusion. ${ }^{10,11}$ If not diagnosed early and treated promptly, it can result in periodontal problems, mobility of mandibular incisors, abrasion of the labial surface of upper incisors, abnormal mandibular growth and pain along with permanent changes in the temporomandibular joint. ${ }^{5,12}$

It is prudent to differentiate skeletal and dental originated anterior crossbites in order to plan an appropriate treatment. ${ }^{8}$ Differentiation can be made by guiding the mandible in its centric relation position and examining the molars and incisor position. If the molars are in class I occlusion and incisors have an edge to edge position, this indicates a dental origin of the anterior crossbite.

According to Proffit, ${ }^{13}$ treatment consists of opening the bite and bringing the affected teeth in the normal position. The main objective of the treatment is to tip the maxillary incisors labially and attaining a positive overbite. ${ }^{14} \mathrm{~A}$ variety of treatment options are present for the correction of anterior crossbite. ${ }^{15}$ Some of the treatment modalities include the use of tongues blades, reverse stainless steel crowns, composite incline planes, Catalan's appliance, Z-springs, acrylic removable appliances and fixed appliance therapy. ${ }^{16}$ Evidence is very low regarding the most efficient method of correcting anterior crossbite. ${ }^{17}$ The choice of treatment depends on factors such as the etiology of crossbite, age of the patient, teeth eruption status, space availability and patient's compliance. $^{12}$

Removable appliances used for the correction of anterior cross bite need patient's compliance therefore they are not successful in non-compliant children and those with special health care needs. ${ }^{18}$ Fixed appliances used for crossbite correction can also pose problems in eating and maintaining oral hygiene resulting in increased caries incidence. They need patient co-operation during cementation and also exert undue heavy forces on the teeth. ${ }^{19}$

In lieu of the above discussion, the current study aims to evaluate a non-invasive treatment approach for the correction of dental crossbite which does not involve any orthodontic appliance. The concept was first proposed by Vasileios Tzatzaki. ${ }^{20,21}$ By placing the occlusal stops on first permanent molars with a suitable material, the bite is raised anteriorly by $1-2 \mathrm{~mm}$ which is within the limits of freeway space. This iatrogenic anterior open bite allows the tongue to push maxillary anterior teeth un-opposingly in the labial direction during normal oral functions such as deglutition, chewing, drinking and speaking. ${ }^{20}$ This results in correction of the anterior crossbite. This approach is simple, cost effective and less technique sensitive. It does not require patient compliance and is easy to maintain. Moreover, it is a painless technique which does not require active orthodontic forces for the correction of dental anterior cross bite.

\section{METHODOLOGY}

The study was conducted in the Pediatric Dentistry Department, Children Hospital, Pakistan Institute of Medical Sciences, Islamabad after ethical approval from the research board. Informed consents were taken from the parents of all the participants.

A convenience sample of sixteen patients (11 females, 5 males with the age range of 7-12years) was included in the study. The inclusion and exclusion criteria are described as follow:

\section{Inclusion Criteria:}

- Children having mixed dentition period

- Presence of dental origin anterior crossbite

- Presence of sufficient mesiodistal space for labial movement of teeth in crossbite

\section{Exclusion Criteria:}

- Presence of anterior open bite

- Previous history of orthodontic treatment

- Medically compromised patients

- Patients with severe intellectual disability

- Skeletal anterior crossbite.

- Patients with temporo-mandibular joint disorders.

Patient history, thorough clinical examination, photographs (intraoral and extra-oral) and radiographs were obtained. After performing oral prophylaxis, Glass ionomer cement (GC, Gold Label Universal Restorative, GC CORPORATION, Tokyo Japan) was placed on the occlusal surface of mandibular first permanent molars bilaterally to build up occlusal stops. Adjustment was made to equalize the height of the occlusal stops on both sides so that it resulted in an anterior open bite of $1 \mathrm{~mm}$.

Patients and parents were instructed to report if any of the occlusal buildup was dislodged. Children were motivated to maintain good oral hygiene and to avoid consumption of sticky foods. They were recalled weekly for two weeks to evaluate the correction of crossbite. After two weeks, occlusal 


\section{Zalan AK/ Maxood A/ Dalili MH/

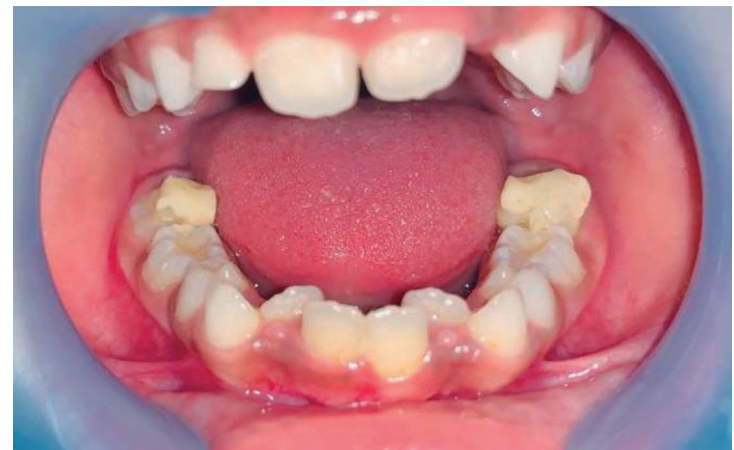

Fig.1: Glass ionomer cement occlusal stops on mandibular permanent molars.

\section{CASE-1}

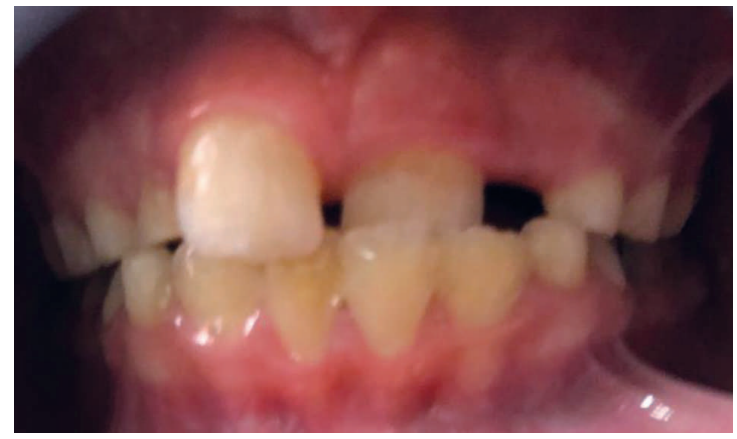

Fig.2.1: Intraoral view showing dental crossbite of maxillary left central incisor.

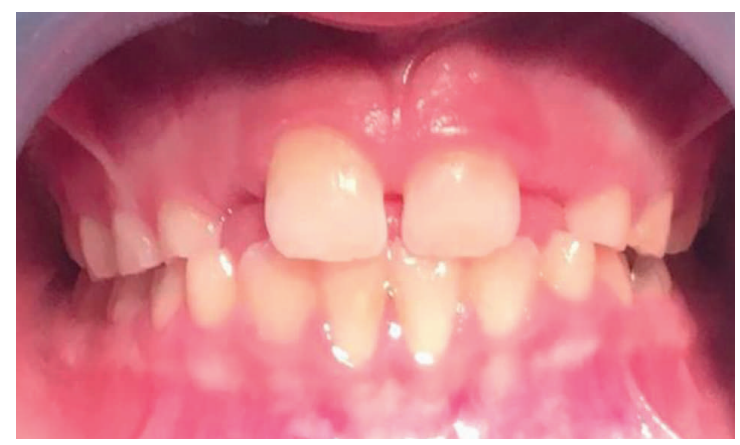

Fig2.2: Posttreatment photograph showing correction of crossbite

stops were removed. Crossbites that were not corrected in this duration were treated with fixed palatal Z-spring appliance.

\section{RESULTS}

The age of the patients ranged from 7 to 11 years with a mean age of 8 years. Of the 16 patients, $5(31 \%)$ were males and $11(68 \%)$ were females .For statistical analysis, SPSS Version 25 was used. Out of 16 patients, 12 patients $(75 \%)$ in the sample had single-tooth crossbite involving one permanent central incisor while 4 patients $(25 \%)$ had
Effect of bite opening on the correction of dental anterior cross bite - A novel approach

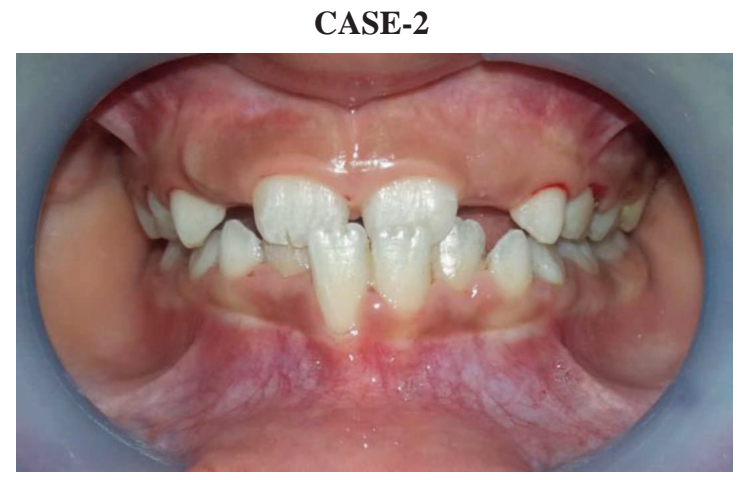

Fig.3.1: Initial intraoral photogrpah showing maxillary central incisors in crossbite

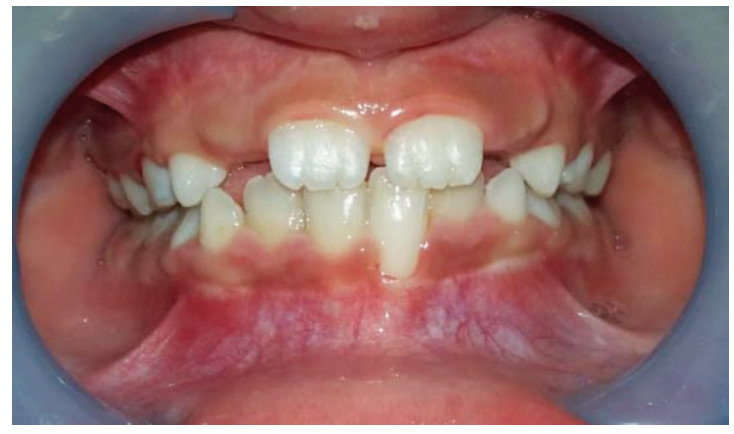

Fig.3.2: Posttreatment photograph after 2 weeks showing correction of anterior crossbite

CASE-3

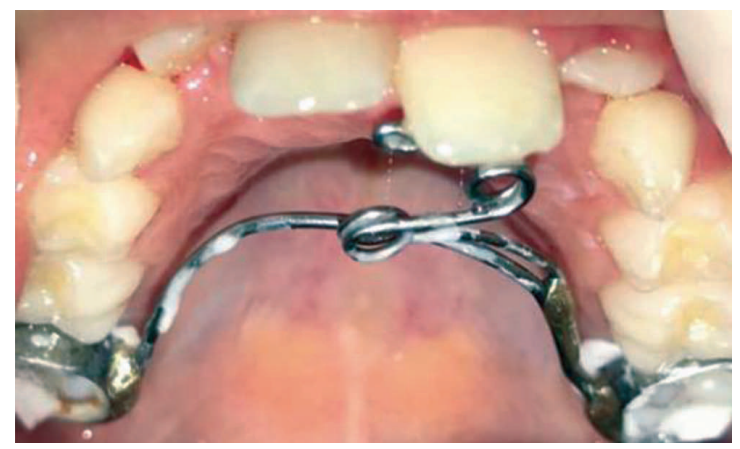

Fig.4: Intraoral photograph showing fixedpalatal z-spring appliance. (sequence of picture is corrected the number of this picture is fig 4)

both permanent central incisors in crossbite. After 2 weeks, $81 \%(\mathrm{n}=13)$ of the patients showed correction in crossbite. Success rate was $80 \%(n=4)$ in males and $81 \%(n=9)$ in females as shown in graph 1 and table 1. Fisher's exact test was applied and the treatment outcome of the procedure showed significant results with $\mathrm{P}=0.04$. Level of significant was taken as $\mathrm{P}<0.05$. All 4 patients with two-teeth crossbite showed correction while it was observed in $75 \%(n=9)$ of the patients with single tooth crossbite. Although all patients showed some changes in positioning of the teeth after one 
week, only one patient showed complete correction of crossbite at one-week follow-up. Three patients showed loss of occlusal stops at one-week follow up which were placed again at the same visit. All of these patients, however, showed correction of crossbite at the next week follow-up.

\section{GRAPH 1}

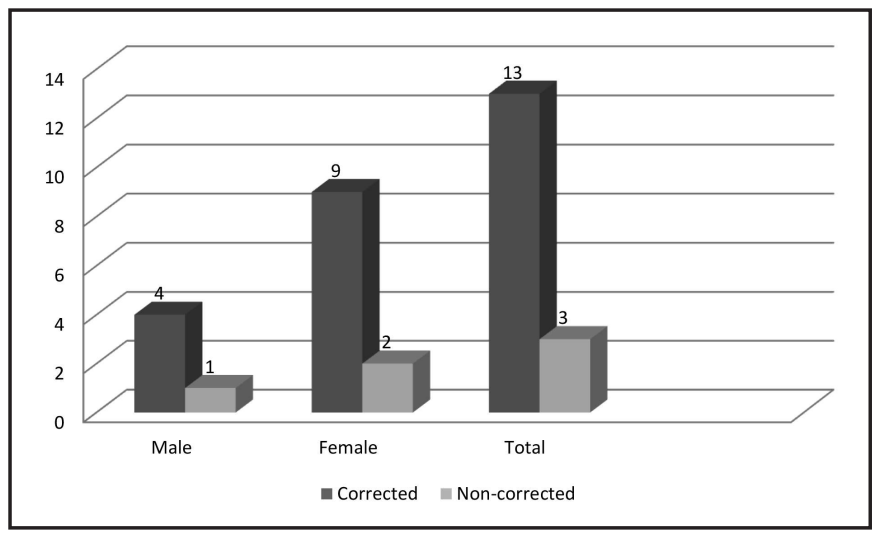

TABLE 1

\begin{tabular}{|l|c|c|}
\hline & $\begin{array}{c}\text { CORRECTED } \\
\mathbf{n}(\%)\end{array}$ & $\begin{array}{c}\text { NON-CORRECTED } \\
\mathbf{n}(\%)\end{array}$ \\
\hline MALE & $4(80)$ & $1(20)$ \\
\hline FEMALE & $9(82)$ & $2(18)$ \\
\hline TOTAL & $13(81)$ & $3(19)$ \\
\hline
\end{tabular}

\section{DISCUSSION}

Dental anterior crossbite is a commonly encountered malocclusion, frequently seen during the early mixeddentition phase. ${ }^{3}$ This condition seldom corrects by itself because the maxillary incisors are locked behind the mandibular incisors. If not addressed early, it can cause abnormal skeletal growth, permanent changes in temporomandibular joint and severe malocclusion. ${ }^{6}$ Thus early treatment to correct anterior crossbite is advisable. The mixed dentition stage offers the greatest opportunity for occlusal guidance and interception of the malocclusion. ${ }^{22}$ If not corrected early, treatment can become more complicated at the later stages of development. ${ }^{23}$

Results of our study showed that anterior cross bite of dental origin can be corrected with this novel technique, which simply involves creation of $1 \mathrm{~mm}$ of anterior open bite by building GIC occlusal stops on mandibular first permanent molars bilaterally as shown in Figure 1. This technique was first proposed by Vasileios Tzatzak ${ }^{20,21}$ who published a series on 5 cases successfully treated by this method. He reported success in both primary and permanent dentition. In our study, a success rate of $81 \%$ was observed at the end of 2 weeks. Similar study conducted by G. Vasilakos and colleagues ${ }^{24}$ showed comparable results with a success of $87.5 \%$. Their study however consisted of an active treatment phase of average 2.5 months. Same technique was employed by Miyajima, ${ }^{25}$ who reported a successful case of anterior crossbite in primary dentition in 1994. However, this approach has not been comprehensively tested yet.

Although patients felt some discomfort on mastication for first few days, none of our patients reported pain in temporo-mandibular joint. It might be because the bite was still within the limits of freeway space.

In our study, crossbite correction was observed in patients irrespective of the involvement of one or two teeth. Figure 2.1 shows pre-op intra-oral picture of an eight years old patient with left maxillary central incisor in crossbite. Occlusal stops were placed on mandibular first permanent molars with GIC. After 2 weeks follow-up, correction of the crossbite was observed as shown in Figure 2.2. Figure3.1 shows preop picture of another patient with both the maxillary incisors in crossbite relation. Figure 3.2 shows post-op picture of the same patient after 2 weeks where correction of the crossbite was observed.

According to Proffit, there is an equilibrial relationship between tongue functions and position of teeth in the arch. ${ }^{26}$ Teeth are under a variety of forces including forces of mastication, and the forces exerted by the lips, cheeks and tongue during various oral functions. It is calculated that the average time when the teeth are under the occlusal forces is 17.5 minutes during 24 hours. ${ }^{27}$ Therefore these forces, whether intermittent or continuous, are sufficient to cause tooth movement. ${ }^{26}$ This theory explains the results of our study where opening of the bite anteriorly, resulted in labial tipping of the maxillary teeth by the unopposed anterior forces of tongue during its normal functioning. Repositioning of the mandibular anterior teeth along the line of arch was also noticed. This might have occurred because of the adaptation of the teeth to the new equilibrium established by the correction of crossbite. The results are also in accordance to Balters's theory, ${ }^{28}$ according to which the equilibrium between the tongue and circumoral muscles is responsible for the shape of the arches and intercuspation. In the current study, as an iatrogenic open bite was created, equilibrium was shifted to an increased forward force of tongue, bringing the affected maxillary teeth labially to the point where a stable overbite relationship was achieved.

Although this is a simple technique for anterior crossbite correction, the clinician should perform a thorough clinical assessment of the patient's facial and dental profiles and make an appropriate diagnosis to determine the cause of the 
crossbite because this method is not recommend when anterior crossbite is due to the involvement of skeletal component. In such cases, orthopedic and more comprehensive treatment would be more appropriate. ${ }^{20}$

GIC occlusal stops were placed only for two weeks to prevent permanent occlusal changes and temporomandibular joint pain and discomfort. Studies in which occlusal stops were placed for longer periods of time reported changes in occlusion and complain of joint pain by the patients..$^{20,24}$

The three patients in whom crossbite correction was not observed at 2 weeks interval were successfully treated with fixed palatal z-spring appliance.

Usually, relapse is not a problem in such cases when a positive overbite is established..$^{29}$ Similarly in our study, no case of relapse was observed in 6 months follow-up. Same results were achieved in other studies. ${ }^{20,24,25}$

The main advantage of this technique is its easy placement as the procedure can be completed in a single visit. The treatment is esthetically acceptable, involves no discomfort and poses less hygienic problems to the patient. It is also cost effective as no appliance fabrication is required. ${ }^{20}$

Different treatment modalities have been proposed for the correction of anterior dental crossbite which includes removable and fixed appliance therapy. These appliances have some disadvantages and shortcomings regarding patient compliance, hygiene maintenance, appliance breakage, de-cementation, oral irritation and discomfort. ${ }^{19}$ The use of removable appliances causes speech difficulty, due to palatal coverage of the appliance, and loosening or breakage of the appliance may also occur. Studies have shown that patients do not comply with the prescribed wear times of removable appliances even when they know that their compliance is objectively recorded therefore compromising the success of the treatment. ${ }^{18}$ In contrast to the use of removable appliances, the proposed technique requires minimal patient compliance and does not cause speech difficulty. On the other hand, fixed appliance therapy is expensive and common problems encountered include compromised oral hygiene, increased caries risk and application of undue, heavy, active orthodontic forces which may cause dental pain, loss of pulp vitality and root resorption. ${ }^{17}$ These problems related to the appliances can be easily overcome with the approach used in this study. Moreover, it can also be effectively used in children with special health care needs because it is quick to apply and requires minimum cooperation by the patient. ${ }^{24}$ It can also be effectively used in patients with poor oral hygiene practices because it does not compromise oral hygiene.

\section{CONCLUSION}

Based on the results of this study, this technique is suggested to be a very easy and effective approach for the correction of dental anterior crossbite without application of active orthodontic forces. However, the clinician should perform a thorough clinical assessment to determine the origin of the crossbite because this approach is not recommended when the anterior crossbite has involvement of a skeletal component.

\section{LIMITATIONS}

Research needs to be done with greater sample size to establish its success and its application in patients with special health care needs.

\section{CONFLICT OF INTEREST}

None to declare

\section{REFERENCES}

1. Dimberg L, Lennartsson B, Söderfeldt B, Bondemark L. Malocclusions in children at 3 and 7 years of age: a longitudinal study. Eur J Orthod. 2013;35:131-37.

https://doi.org/10.1093/ejo/cjr110

2. Tsai HH. Components of anterior crossbite in the primary dentition. ASDC J Dent Child. 2001;68:27-32

3. Major PW, Glover K. Treatment of anterior cross-bites in the early mixed dentition. J Can Dent Assoc. 1992;58:574-78.

4. Lux CJ, Dücker B, Pritsch M, Komposch G, Niekusch U. Occlusal status and prevalence of occlusal malocclusion traits among 9-yearold schoolchildren. Eur J Orthod. 2009;31:294-99.

https://doi.org/10.1093/ejo/cjn116

5. Vithanaarachchi SN, Nawarathna LS. Prevalence of anterior cross bite in preadolescent orthodontic patients attending an orthodontic clinic. Ceylon Med J. 2017;62:189-92.

https://doi.org/10.4038/cmj.v62i3.8523

6. Ulusoy AT, Bodrumlu EH. Management of anterior dental crossbite with removable appliances. Contemp Clin Dent. 2013;4:223. https://doi.org/10.4103/0976-237X.114855

7. Singh G, editor. Textbook of orthodontics. JP Medical Ltd; 2015 Feb 20.

8. Park JH, Kim TW. Anterior crossbite correction with a series of clear removable appliances: A case report. J EsthetRestor Dent. 2009;21:149-59.

https://doi.org/10.1111/j.1708-8240.2009.00257.x

9. Bayrak S, Tunc ES. Treatment of anterior dental crossbite using bonded resin-composite slopes. Eur J Dent. 2008;2:303-06. https://doi.org/10.1055/s-0039-1697397 


\section{Zalan AK/ Maxood A/ Dalili MH/ Zaman H/ Zubairy KK/ Babar P/ Anser M}

10. Iodice G, Danzi G, Cimino R, Paduano S, Michelotti A. Association between posterior crossbite, skeletal, and muscle asymmetry: a systematic review. Eur J Orthod. 2016;38:638-51.

https://doi.org/10.1093/ejo/cjw003

11. Vakiparta MK, Kerosuo HM, Nystrom ME, Heikinheimo KA. Orthodontic treatment need from eight to 12 years of age in an early treatment oriented public health care system: a prospective study. Angle Orthod. 2005;75:344-49.

12. Vadiakas G, Viazis AD. Anterior crossbite correction in the early deciduous dentition. Am J Orthod Dentofacial Orthop.1992;102:16062

https://doi.org/10.1016/0889-5406(92)70029-A

13. W. R. Proffit, H. W. Fields, and D. M. Sarve, Contemporary Orthodontics, Mosby, St. Louis, Mo, USA, 3rd edition, 1999.

14. Jacobs SG. Teeth in cross-bite: the role of removable appliances. Aust Dent J. 1989;34:20-8. https://doi.org/10.1111/j.1834-7819.1989.tb03000.x

15. Borrie F, Bearn D. Early correction of anterior crossbites: a systematic review. J Orthod. 2011;38:175-84.

https://doi.org/10.1179/14653121141443

16. Management of anterior dental crossbite with removable appliances. Contemp Clin Dent. 2013;4:223.5;37:123-27. https://doi.org/10.4103/0976-237X.114855

17. Wiedel AP, Bondemark L. Fixed versus removable orthodontic appliances to correct anterior crossbite in the mixed dentition-a randomized controlled trial. Eur J Orthod. 2015;37:123-27.

https://doi.org/10.1093/ejo/cju005

18. Tsomos G, Ludwig B, Grossen J, Pazera P, Gkantidis N. Objective assessment of patient compliance with removable orthodontic appliances: a cross-sectional cohort study. Angle Orthod. 2014;84: 56-61.

https://doi.org/10.2319/042313-315.1
Effect of bite opening on the correction of dental anterior cross bite - A novel approach

19. Bukhari OM, Sohrabi K, Tavares M. Factors affecting patients' adherence to orthodontic appointments. Am J Orthod Dentofacial Orthop. 2016;149:319-24.

https://doi.org/10.1016/j.ajodo.2015.07.040

20. Tzatzakis V, Gidarakou IK. A new clinical approach for the treatment of anterior crossbites. World J Orthod. 2008;9:355-65.

21. Tzatzakis V, Gidarakou I. Correction of anterior crossbite using occlusal build-ups. J Clin Orthod. 2007;41:393.

22. Kocadereli I. Early treatment of posterior and anterior crossbite in a child with bilaterally constricted maxilla: report of case. ASDC J Dent Child. 1998;65:41-6.

23. Tse CS. Correction of single-tooth anterior crossbite. J Orthod. 1997;31:188-90.

24. Vasilakos G, Koniaris A, Wolf M, Halazonetis D, Gkantidis N. Early anterior crossbite correction through posterior bite opening: a 3D superimposition prospective cohort study. Eur J Orthod. 2018;40:364-71.

https://doi.org/10.1093/ejo/cjx074

25. Miyajima K, Imamura S, Fuwa Y, Nakamura S, Nagahara K, Tsuchiya T, Kurosu K, Iizuka T. Posterior bite raising effects on a primary anterior crossbite case. J Clin Pediatr Dent. 1995;19:131-4.

26. Proffit WR. Equilibrium theory revisited: factors influencing position of the teeth. The Angle Orthodontist. 1978;48:175-86.

27. Hickey JC, Zarb GA, Bolender CL. Prosthodontic treatment for edentulous patients. St. Louis: CV Mosby Company; 1975.

28. Balters W. Eine Einführung in die Bionatorheilmethode: ausgewählteSchriften und Vorträge. Hölzer; 1973.

29. Croll TP. Fixed inclined plane correction of anterior crossbite of the primary dentition. J Periodontics. 1984;9:84-97. 